\title{
Preventing maternal phenylketonuria (PKU) syndrome: important factors to achieve good metabolic control throughout pregnancy
}

\author{
Carmen Rohde ${ }^{1 *} \mathbb{D}$, Alena Gerlinde Thiele ${ }^{1}$, Christoph Baerwald ${ }^{2}$, Rudolf Georg Ascherl ${ }^{1}$, Dinah Lier ${ }^{3}$, \\ Ulrike Och ${ }^{4}$, Christina Heller ${ }^{5}$, Alexandra Jung ${ }^{6}$, Kathrin Schönherr ${ }^{7}$, Monika Joerg-Streller ${ }^{8}$, Simone Luttat ${ }^{9}$, \\ Sabine Matzgen ${ }^{10}$, Tina Winkler $^{11}$, Stefanie Rosenbaum-Fabian ${ }^{12}$, Oxana Joos ${ }^{13}$ and Skadi Beblo ${ }^{1}$
}

\begin{abstract}
Background: Insufficient metabolic control during pregnancy of mothers with phenylketonuria (PKU) leads to maternal PKU syndrome, a severe embryo-/fetopathy. Since maintaining or reintroducing the strict phenylalanine (Phe) limited diet in adults with PKU is challenging, we evaluated the most important dietary and psychosocial factors to gain and sustain good metabolic control in phenylketonuric women throughout pregnancy by a questionnaire survey with 38 questions concerning therapy feasibility. Among them, the key questions covered 5 essential items of PKU care as follows: General information about maternal PKU, PKU training, diet implementation, individual metabolic care, personal support. In addition, all participating PKU mothers were asked to estimate the quality of their personal metabolic control of the concluded pregnancies. 54 PKU mothers with 81 pregnancies were approached at 12 metabolic centers in Germany and Austria were included. According to metabolic control, pregnancies of PKU women were divided in two groups: group "ideal" (not more than 5\% of all blood Phe concentrations during pregnancy $>360 \mu \mathrm{mol} / / ; \mathrm{n}=23$ ) and group "suboptimal" (all others; $\mathrm{n}=51$ ).
\end{abstract}

Results: The demand for support was equally distributed among groups, concerning both amount and content. Personal support by the direct social environment (partner, family and friends) ("suboptimal" $71 \%$ vs "ideal" $78 \%$ ) as well as individual metabolic care by the specialized metabolic center (both groups around 60\%) were rated as most important factors. The groups differed significantly with respect to the estimation of the quality of their metabolic situation ( $p<0.001)$. Group "ideal" presented a 100\% realistic self-assessment. In contrast, group "suboptimal" overestimated their metabolic control in $53 \%$ of the pregnancies. Offspring of group "suboptimal" showed clinical signs of maternal PKU-syndrome in 27\%.

Conclusion: The development of training programs by specialized metabolic centers for females with PKU in child bearing age is crucial, especially since those mothers at risk of giving birth to a child with maternal PKU syndrome are not aware of their suboptimal metabolic control. Such programs should provide specific awareness training for the own metabolic situation and should include partners and families.

Keywords: Maternal PKU syndrome, Phenylketonuria, Training program, mPKU, Maternal PKU, Pregnancy, PKU

\footnotetext{
*Correspondence: Carmen.Rohde@medizin.uni-leipzig.de ${ }^{1}$ Hospital for Children and Adolescents, Centre for Pediatric Research Leipzig (CPL), Department of Women and Child Health, University Hospital, University of Leipzig, Leipzig, Germany

Full list of author information is available at the end of the article
}

\section{Background}

Phenylketonuria (PKU) is the most frequent inborn error of amino acid metabolism. Untreated, it leads to severe psychomotor retardation. Since establishment of 
newborn screening in the 1970s and early and continuous treatment throughout life patients develop normally [1-4]. Most women with PKU live a normal life and family planning becomes an important issue. In this context, ideal metabolic control during pregnancy is absolutely necessary to prevent maternal PKU syndrome, a severe embryo-/fetopathy. Characteristic signs are microcephaly, mental retardation, growth retardation and birth defects including congenital heart disease $[3,5,6]$. Phenylalanine (Phe) is an essential amino acid and is shuttled actively from the mother to the unborn by the placenta $[1,7]$. Therefore, fetal blood Phe concentrations are up to twice as high as their mothers' $[1,7]$. High maternal Phe concentrations during conception and pregnancy severely impair organogenesis and growth, and maternal PKU syndrome ensues if the mother's phenylalanine (Phe) concentrations rise above $360 \mu \mathrm{mol} / \mathrm{l}$ during pregnancy. To prevent the birth of a child with maternal PKU syndrome, mothers must therefore keep their plasma Phe concentration between 120 and $360 \mu \mathrm{mol} / \mathrm{l}$ [8-10]. Unplanned pregnancies should be strictly avoided.

It is a challenge to achieve good metabolic control throughout pregnancy. After mandatory strict dietary treatment during childhood with ideal blood Phe concentrations between 42 and $240(-360 \mu \mathrm{mol} / \mathrm{l})$, higher levels are accepted from puberty onwards (up to 600 or $900 \mu \mathrm{mol} / \mathrm{l})$ [2, 3]. It is recommended that all women with PKU considering pregnancy resume a strict diet.

We hypothesized that currently implemented structures are insufficient to fulfill patients' needs in this sensitive situation. Specialized PKU care for adults, especially with respect to care during pregnancy, is still scarce [4, $11,12]$ and most gynecologists and obstetricians are unfamiliar with this disease and the effects of typical pregnancy related issues on the metabolic control in PKU. Attempts to improve care include home visitation programs [13], hospitalization during pregnancy [14], or accompanying psychotherapy [15], all with inconclusive results.

To establish a structured program for PKU pregnancy care, it is important to identify factors which are helpful for women with PKU to restart a strict low-phe diet before conception and during pregnancy. We therefore performed a cross-sectional multicenter evaluation at 12 German speaking metabolic centers with the focus on women's needs to support this important phase of life.

\section{Methods}

The metabolic center of Leipzig, Germany, designed a retrospective, multi-center evaluation. It was approved by the ethics committee at the University of Leipzig Medical Faculty and local ethics committees of participating centers. The study was registered with the German Clinical Trial register (registration numbers 027-16-01022016, DRKS 00013706) at the International Clinical Trials Registry Platform. At the participating centers (Berlin, Cottbus, Erlangen-Nürnberg, Freiburg, Giessen, Greifswald, Jena, Leipzig, Magdeburg, Münster, Reutlingen, all in Germany, and Innsbruck, Austria), all mothers with PKU were approached at routine clinic visits between April 2016 and January 2018. Participants gave written informed consent. All pregnancies were already concluded at the time of answering a two-part multiple choice questionnaire, specifically designed for this purpose (Additional file 1). One case of termination of pregnancy due to antenatal evidence of major malformation has been reported from one of the treatment centers; for lack of any further information, this case could not be included. Mothers with more than one pregnancy were asked to answer the questionnaire separately for each pregnancy.

Mothers with PKU were asked to answer 36 general questions about former and current treatment and diet implementation as well as pregnancy outcome. In addition, two extended key questions concerning diet feasibility during pregnancy ("What was helpful for you keeping the diet during pregnancy?" and "What have you missed during pregnancy?") were provided. Here, 22 answering options were offered, and patients could mark as many options as they felt appropriate (Additional file 1). Answering options marked as "helpful" or "missed" were summed up to "important factors" and reasserted to cover 5 essential items as follows: General information about matsternal PKU, PKU training, diet implementation, individual metabolic care, personal support. As multiple answers were possible, the given numbers are not adding up to the total $\mathrm{n}$, and the given percentages are not adding up to 100. Additionally, participants could provide personal statements, almost only used by single patients repeating already offered answers within the multiple choice part.

To gain additional information about knowledge and awareness of metabolic control during pregnancy, the question "How would you estimate your metabolic control during pregnancy?" was included in the questionnaire. Four responses were offered: "almost all (>80\%) measured Phe concentrations were $<240 \mu \mathrm{mol} / \mathrm{l}$ ", "more than half of all measured Phe concentrations were $<240 \mu \mathrm{mol} / \mathrm{l}$ ", "less than half of all measured Phe concentrations were $<240 \mu \mathrm{mol} / \mathrm{l}$ ", and "almost all (>80\%) measured Phe concentrations were $>240 \mu \mathrm{mol} / \mathrm{l}$ ". We chose the cutoff of $240 \mu \mathrm{mol} / \mathrm{l}$ because this target value was widely recommended at the time of the mothers' pregnancies [1, 7]. Of note, all pregnancies had already been concluded. Therefore, 
these data represent the mothers own retrospective impression of metabolic control.

The second part of the questionnaire included data about metabolic control before and during pregnancy. These data were provided by the treating metabolic centers.

According to metabolic control, we divided pregnancies in two subgroups: group "ideal" presented metabolic control with no more than $5 \%$ of all blood Phe concentrations during pregnancy above $360 \mu \mathrm{mol} / \mathrm{l}$; group "suboptimal" included all other pregnancies.

Statistical analysis was performed using SPSS 25 (IBM). Group comparisons were performed with respect to patient characteristics, metabolic control, as well as selfestimation of own metabolic control during pregnancy and "important factors" for dietary control. Since data were not normally distributed, Mann-Whitney-U test was used to perform group comparisons, with weighting according to group sizes. Significance was assumed for $\mathrm{p}<0.05$.

\section{Results}

65 mothers with PKU could be approached by the respective treatment centers, 54 were willing to answer the questionnaire for a total number of 81 pregnancies. 7 questionnaires were excluded from analysis: 2 because patients received cofactor treatment with sapropterin dihydrochloride during pregnancy and another 5 where no laboratory data were available (technical loss of data in the respective treatment center). Altogether, 74 evaluable questionnaires could be analyzed for either the first $(\mathrm{n}=50)$, second $(\mathrm{n}=21)$ or third $(\mathrm{n}=3)$ pregnancy.

23 pregnancies (31\%) could be assigned to the group "ideal". With one exception, all of these pregnancies were planned. The remaining 51 pregnancies (69\%) were assigned to the group "suboptimal", of which 11 pregnancies were unplanned. In case of repeated pregnancies, each of these was assorted to the respective category. All multiple pregnancies were found to be in the same group with four exceptions. Three mothers showed better metabolic control during the first compared to subsequent pregnancies.

Patient characteristics and data about metabolic control as well as offspring outcome of both groups are shown in Tables 1 and 2 . The groups differed significantly regarding mean blood Phe values $(\mathrm{p}<0.001)$ and mean percentage (\%) of Phe values above the therapeutic range $(\mathrm{p}<0.001)$ (Table 2). Mothers of group "ideal" had a significantly higher level of education (Table 1). No differences could be found regarding the following parameters: Phe tolerance, frequency of blood Phe testing, kind of diet implementation (calculating or estimating Phe consumption), and perceived burden of keeping the diet, number of pregnancies, and mothers' mean age at the beginning of pregnancy (Table 1). However, offspring of mothers of group "suboptimal" showed suspicious signs for maternal PKU syndrome in $27 \%$, whereas none of the offspring from mothers with ideal metabolic control seems to be affected.

Important items to maintain metabolic control throughout pregnancy and their individual ranking are shown in Fig. 1 for subgroups "ideal" and "suboptimal".

Both groups seem to need an equal amount of support. Most frequently mentioned important factor in all proposed items in both groups was identified as "support by my partner", next to "individual metabolic care" by the metabolic center.

Comparing the frequency of answering options and, therefore, the importance of different factors between groups, no significant differences could be found with four exceptions. Patient group "suboptimal" mentioned significantly more often "group training" and "hospitalization" as important factors.

In contrast, group "ideal" mentioned significantly more often an "official support group" and "support by other PKU mothers".

The data about their retrospective self-estimation of metabolic control during pregnancy at the time of the questionnaire is shown in Table 3. While the subgroup "ideal" showed a realistic estimation, the subgroup "suboptimal" overestimated their own metabolic control and guessed it being far better than the data proved it to be in $53 \%$ of the pregnancies. This difference between groups regarding self-assessment was significant $(\mathrm{p}<0.001)$ (Table 3$)$.

Concerning the nutritional aspects in the questionnaire, no differences in importance of specific special low protein foods for maintaining metabolic control could be revealed between groups. Therefore, only cumulative data is shown in Tables 4 and 5 . In $96 \%$ of the patients special low protein cereal foods (bread and buns) were the most helpful products to create a sensible dietary plan.

This was followed by low protein milk replacement, whereas all other foods are obviously of far less importance. Only $11 \%(n=8)$ of the PKU women mentioned low protein pasta (Table 4).

The preferred choice of Phe free amino acid mixtures is shown in Table 5. Again, no differences between the subgroups "ideal" and "suboptimal" were found. The data showed that the preferred amino acid mixtures were non-flavored powders and ready-to-drink mixes. Except for amino-acid pills, special designed products such as bars or "puddings" were unpopular (Table 5). 
Table 1 Patient characteristics

\begin{tabular}{|c|c|c|c|}
\hline & $\begin{array}{l}\text { Group "ideal" } \\
\mathrm{n}=23\end{array}$ & $\begin{array}{l}\text { Group "suboptimal" } \\
\mathrm{n}=51\end{array}$ & $\begin{array}{l}\text { p (Mann- } \\
\text { Whitney-U) }\end{array}$ \\
\hline \multicolumn{4}{|l|}{ Patients:n (\%) } \\
\hline Planned pregnancies & $22(96)$ & $40(78)$ & 1 \\
\hline Unplanned pregnancies & $1(4)$ & $11(22)$ & 1 \\
\hline \multicolumn{4}{|l|}{ Pregnancies: $n(\%)$} \\
\hline First & $18(78)$ & $31(61)$ & 1 \\
\hline Second & $5(22)$ & $16(31)$ & 1 \\
\hline Third & $0(0)$ & $4(8)$ & \\
\hline \multicolumn{4}{|l|}{ Phe tolerance before pregnancy (mg/day) } \\
\hline Mean (SD) & $587(235)$ & $572(264)$ & 0.798 \\
\hline Median (IQR) & $560(400-787)$ & $500(362-800)$ & \\
\hline Range & 250-950 & $300-1200$ & \\
\hline \multicolumn{4}{|l|}{ Phe-tolerance known before pregnancy: $n$ (\%) } \\
\hline Known & $12(52)$ & $28(55)$ & 1 \\
\hline Unknown & $11(48)$ & $23(45)$ & 1 \\
\hline \multicolumn{4}{|l|}{ Blood Phe-analyses during pregnancy (n) } \\
\hline Mean (SD) & $38(14)$ & $33(12)$ & \\
\hline Median (IQR) & $35(29-42)$ & $34(28-40)$ & 0.345 \\
\hline Range & $17-79$ & $5-66$ & \\
\hline \multicolumn{4}{|l|}{ Diet implementation: $n(\%)$} \\
\hline Calculation of all foods & $2(9)$ & $10(20)$ & 0.320 \\
\hline Calculation of all foods except fruit, vegetables and low protein foods & $0(0)$ & $1(2)$ & 1 \\
\hline No consumption of protein-rich foods and estimation of Phe-intake & $7(30)$ & $14(27)$ & 1 \\
\hline Consumption of protein-rich foods and estimation of Phe-intake & $9(39)$ & $12(24)$ & 0.265 \\
\hline None & $5(22)$ & $14(27)$ & 0.776 \\
\hline \multicolumn{4}{|l|}{ Feeling about diet: $n(\%)$} \\
\hline Very hard & $2(9)$ & $5(10)$ & 1 \\
\hline Hard & $4(17)$ & $13(25)$ & 0.558 \\
\hline Easy & $14(57)$ & $22(43)$ & 0.211 \\
\hline Very easy & $4(17)$ & $10(20)$ & 1 \\
\hline \multicolumn{4}{|l|}{ Age of mothers at beginning of pregnancy (years) } \\
\hline Mean (SD) & $29.5(4,3)$ & 28.90 & \\
\hline Median (IQR) & $29(26-33)$ & $29(26-32)$ & 0.258 \\
\hline Range & $21-38$ & $19-39$ & \\
\hline \multicolumn{4}{|l|}{ Mother's highest achieved degree of school education: $n$ (\%) } \\
\hline Primary school & $0(0)$ & $0(0)$ & 1 \\
\hline School for mentally handicapped children & $0(0)$ & $2(4)$ & 0.566 \\
\hline 9th grade & $0(0)$ & $6(12)$ & 0.168 \\
\hline 10th grade & $10(43)$ & $29(57)$ & 0.323 \\
\hline 12th grade & $13(57)$ & $14(27)$ & $0.013^{*}$ \\
\hline
\end{tabular}

\section{Discussion}

Gaining and maintaining good metabolic control while planning and during pregnancy is the most important factor for women with PKU who wish to give birth to healthy children. Constant blood Phe concentrations $<360 \mu \mathrm{mol} / \mathrm{l}$ are the best prevention of maternal PKU syndrome $[4,6,8,9,16]$. However, adolescents and adults with PKU are often not compliant to the prescribed diet, irrespectively of being male or female [17-20]. Programs to help women with PKU to achieve sufficient metabolic control during pregnancy have been demanded for decades $[8,21,22]$. Attempts include home visitation programs [13] hospitalization during pregnancy [14], or accompanying psychotherapy [15], all with 
Table 2 Metabolic control

\begin{tabular}{|c|c|c|c|}
\hline & $\begin{array}{l}\text { Group "ideal" } \\
n=23\end{array}$ & $\begin{array}{l}\text { Group "suboptimal" } \\
n=51\end{array}$ & $\begin{array}{l}\text { p } \\
\text { (Mann-Whitney U) }\end{array}$ \\
\hline \multicolumn{4}{|l|}{ Blood Phe concentration during pregnancy ( $\mu$ mol/l) } \\
\hline Range of all measurements & $6-762$ & $8-1195$ & \\
\hline Mean of mean values (SD) & $158(35)$ & $292(160)$ & \\
\hline Median of mean values (IQR) & $154(123-188)$ & $245(202-292)$ & $<0.001$ \\
\hline Range of mean values & $101-225$ & $115-882$ & \\
\hline \multicolumn{4}{|l|}{ Phe > 360 umol/l:n (\%) } \\
\hline Mean (SD) & $1.3(2)$ & $26(25)$ & \\
\hline Median (IQR) & $0(0-3)$ & $34(28-40)$ & $<0.001$ \\
\hline range & $0-5$ & $6-100$ & \\
\hline Clinical signs of maternal PKU syndrom: $n^{*}(\%)$ & 0 & $14(27)$ & n.a \\
\hline Heart defect & 0 & $1(2)$ & \\
\hline Microcephaly & 0 & $4(8)$ & \\
\hline Microsomia & 0 & $2(4)$ & \\
\hline Behavior abnormalitie & 0 & $7(14)$ & \\
\hline Developmental delay & 0 & $6(12)$ & \\
\hline Special school & 0 & $6(12)$ & \\
\hline
\end{tabular}

* 7 children suffering from more than one clinical sign suspicious of maternal PKU syndrome

inconclusive results. The study presented here aimed to identify most important factors to gain and sustain good metabolic control in phenylketonuric women throughout pregnancy, assuming that the current programs of health care systems might be off target or insufficient. Using an especially designed two-part multiple choice questionnaire, we could identify factors, which mothers indicated as important to support good metabolic control during 74 concluded pregnancies.

In a previous study, we found that a cohort of well treated PKU patients show about $30 \%$ of blood Phe concentrations above the recommended range [23], which is in accordance with data from another recent investigation [26]. Clearly, this amount of Phe-concentrations off target seemed to us to be insufficient during pregnancy. In contrast, to expect that not a single sample would display elevated blood Phe concentrations is not a realistic approach. As a compromise, we allowed up to 5\% of elevated blood Phe concentrations during pregnancy and still defined this as "ideal" metabolic control. Accordingly, we divided the pregnancies into two groups "ideal" and "suboptimal".

Phe tolerance, frequency of blood Phe testing, dietary management, burden of keeping the diet, number of pregnancies and mothers' mean age at the beginning of pregnancy were comparable between these groups.

However, self-estimation of metabolic control shows significant deficiencies in the group "suboptimal", and signs of maternal PKU syndrome could be revealed in almost $30 \%$ of their offspring, whereas none of the children born to mothers with "ideal" metabolic control was affected. Interestingly, group "ideal" showed significantly higher school education compared to group "suboptimal".

Concerning most important factors to support good metabolic control, both groups specified "personal support", especially "support by my partner" and "support by my family and friends". This was followed by specialty care offered by the metabolic center ("contact to a metabolic center before planning a pregnancy", "informative conversation with current dietician", "informative conversation with current physician").

Other options, such as specific printed information material or samples of special low-protein food, were less important. Only the group "suboptimal" listed "group training" and "hospitalization" as helpful factors. These patients seem to recognize their need to improve metabolic control and therefore are even willing to undergo hospitalization for a while. In contrast group "ideal" was looking for "official support group" and contact to "other PKU mothers".

Our most important finding is that a substantial proportion of pregnant PKU patients had an inaccurate self-estimation of their metabolic situation. This accounts for a volatile situation since this overestimation is in coincidence with suboptimal control and signs of maternal PKU syndrome in the offspring. The currently implemented patient education, even in specialized outpatient clinics, seems therefore insufficient. 


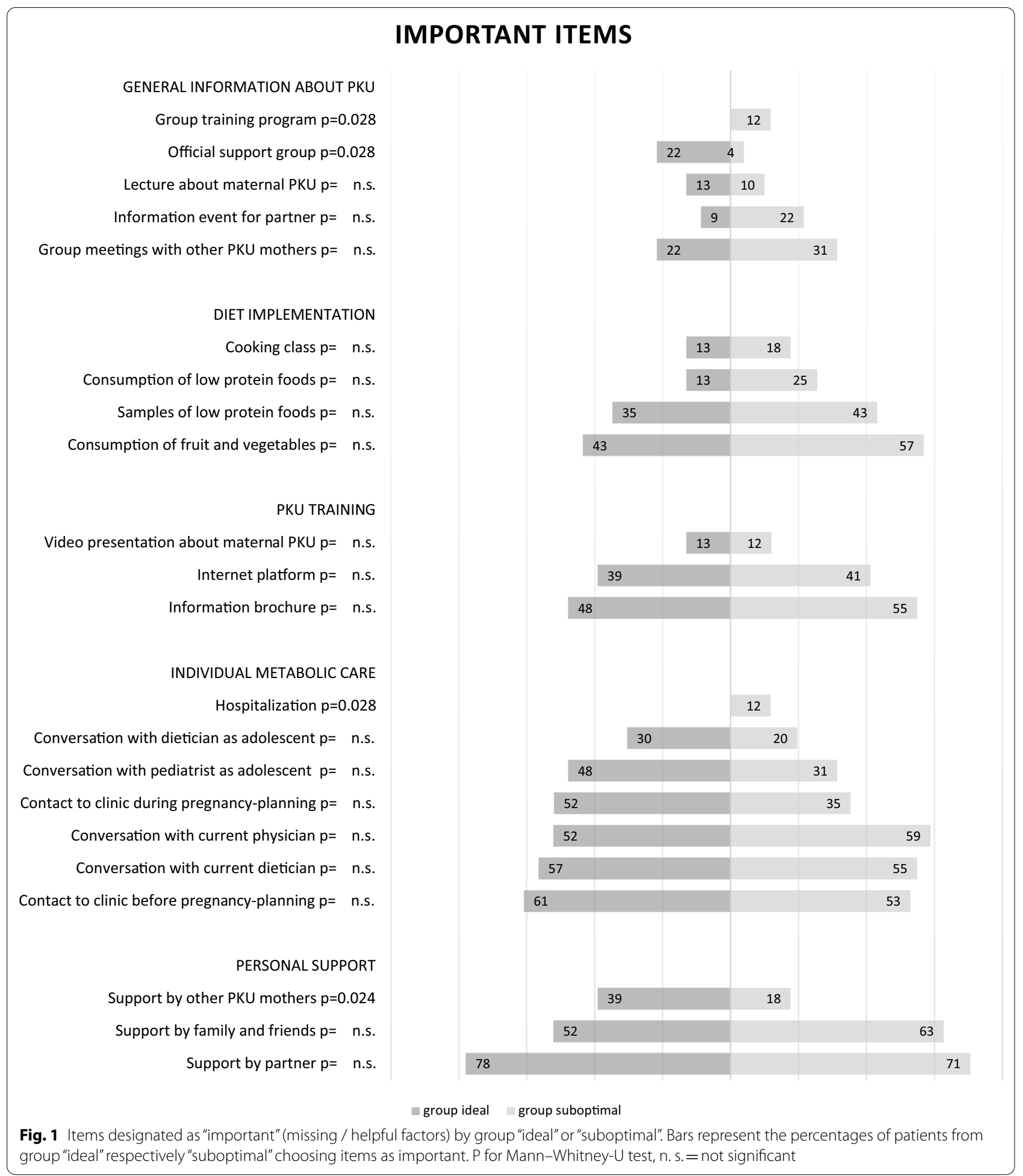

Establishment of separate clinics for adults geared toward adolescents with PKU can support the process of taking over responsibility for their own disease awareness and treatment $[20,24]$. However, the process to become autonomous cannot be performed as a one-way procedure by working only with the patients. Special training of the respective parents on how to allow more responsibility through their children should be implemented 
Table 3 Estimation of own metabolic control during pregnancy

\begin{tabular}{|c|c|c|c|c|c|}
\hline & \multicolumn{2}{|l|}{ Group "ideal" } & \multicolumn{2}{|c|}{ Group "suboptimal" } & \multirow{3}{*}{$\begin{array}{l}\text { P (Mann- } \\
\text { Whitney-U } \\
\text { test) }\end{array}$} \\
\hline & \multicolumn{2}{|l|}{$\mathrm{n}=23$} & \multicolumn{2}{|l|}{$\mathrm{n}=51$} & \\
\hline & Realistic n (\%) & $\begin{array}{l}\text { Overestimation } \\
\mathrm{n}(\%)\end{array}$ & Realistic n (\%) & $\begin{array}{l}\text { Overestimation } \\
\mathrm{n}(\%)\end{array}$ & \\
\hline Almost all (> 80\%) blood Phe concentrations $<240 \mu \mathrm{mol} / \mathrm{l}$ & $16(70)$ & 0 & $9(18)$ & $18(35)$ & \\
\hline $\begin{array}{l}\text { More than half }(>50 \%) \text { of all blood Phe concentra- } \\
\text { tions }<240 \mu \mathrm{mol} / \mathrm{l}\end{array}$ & $5(18)$ & $1(4)$ & $8(16)$ & $9(18)$ & \\
\hline $\begin{array}{l}\text { Less than half }(<50 \%) \text { of all blood Phe concentra- } \\
\text { tions }<240 \mu \mathrm{mol} / \mathrm{l}\end{array}$ & 0 & 0 & $5(10)$ & 0 & \\
\hline Almost all (> 80\%) blood Phe concentrations $>240 \mu \mathrm{mol} / \mathrm{l}$ & 0 & 0 & 0 & 0 & \\
\hline Total & $21(88)$ & $1(4)$ & $22(44)$ & $27(53)$ & $<0.001$ \\
\hline Question not answered & $2(8)$ & $2(4)$ & & & \\
\hline
\end{tabular}

Table 4 Most helpful low protein food

\begin{tabular}{ll}
\hline & $\mathbf{n}=\mathbf{7 4}(\%)$ \\
\hline Bread, buns & $71(96)$ \\
Milk replacer & $43(58)$ \\
Cakes, cookies & $19(26)$ \\
Meet replacer & $15(20)$ \\
Cheese replacer & $13(18)$ \\
Sweets, chocolate, bars & $12(16)$ \\
Convenient foods & $9(12)$ \\
Noodles, pasta & $8(11)$ \\
\hline
\end{tabular}

Table 5 Preferred pharmaceutical form of amino acid mixture

\begin{tabular}{lc}
\hline & $\mathbf{n}=\mathbf{7 4}(\%)$ \\
\hline Non-flavoured powder, box & $23(31)$ \\
Ready-to-drink mixes & $21(28)$ \\
Pills & $20(27)$ \\
Non-flavoured powder, sachets & $16(22)$ \\
Flavoured powder, sachets & $7(9)$ \\
Flavoured powder, box & $2(3)$ \\
Ready-to-eat bars & $2(3)$ \\
"Pudding" & $1(1)$ \\
\hline
\end{tabular}

- comparable to how it has already been shown in the field of other chronic diseases such as type I diabetes [25]. Differences in general educational levels in patients and their families have to be incorporated in this respect, calling for a maximum of individual support of PKU patients from early childhood onwards not only for their own life but also in preparation for the next generation.

Establishment of clinic visits for adolescents without their parents is an important part towards this development. By this, the transition to the adult medical care can be prepared and started to ensure continuous contact to the metabolic center [26, 27].

Metabolic centers should actively encourage the partner's participation in clinic visits, educational activities or consultations with dietitians, as personal support by the partner or/and family members was rated as the most important factor in both groups to achieve good metabolic control. Specialized programs approaching partners or couples should be implemented which help to prepare for pregnancy.

As a consequence of this study's observations, the Leipzig metabolic center has introduced a targeted weekend seminar incorporating most of the aspects discussed here for young PKU women and their partners which already achieves cross-regional attention [28].

The main limitation of the study comprises the restricted variability within the investigated group. Most of the participating PKU women are still under constant specialized care in one of the 12 metabolic centers. PKU women without specialized care or after dropping out of treatment and care could not be reached by the chosen approach. This is of importance, as the risk of giving birth to a child with maternal PKU syndrome is continuously rising, because the number of healthy PKU women reaching childbearing age is increasing [29, 30]. The number of unreported pregnancies is probably high and maternal PKU syndrome in an offspring is not easy to detect as severity varies. Pediatricians caring for children with developmental delay might even not be aware of the mother's PKU.

\section{Conclusion}

Facing the constantly rising number of children delivered by PKU mothers, the development of training programs for PKU females in child bearing age is crucial. Since the importance of personal communication with 
partners and families as well as PKU professionals within the specialized healthcare system could not be overruled by other important items, these programs should be tailored according to the specific needs of this patient group, including an early start of transition from pediatric to continuous adult care and education of partners of all young women with PKU.

\section{Abbreviations}

PKU: Phenylketonuria; Phe: Phenylalanine; DRKS: Deutsches Register klinischer Studien (German Clinical Trials Register.

\section{Supplementary Information}

The online version contains supplementary material available at https://doi. org/10.1186/s13023-021-02108-5.

Additional file 1. Survey Maternal Phenylketonuria.

\section{Acknowledgements}

The authors would like to thank the patients for their interest and participation.

\section{Authors' contributions}

CR, AGT and SB formed the concept and designed the work, all authors, except RGA, acquired patients and patient data. CR and RGA analyzed the data, SB and CR interpreted the data, and drafted the manuscript. All authors revised the draft and approved the manuscript and the modified version. All authors have agreed both to be personally accountable for the author's own contributions and to ensure that questions related to the accuracy or integrity of any part of the work, even ones in which the author was not personally involved, are appropriately investigated, resolved, and the resolution documented in the literature. All authors read and approved the final manuscript.
\end{abstract}

\section{Funding}

Open Access funding enabled and organized by Projekt DEAL. The authors did not receive funding for this work.

\section{Availability of data and materials}

The datasets used and/or analysed during the current study are available from the corresponding author on reasonable request.

\section{Declarations}

\section{Ethics approval and consent to participate}

The ethics committee at the University of Leipzig Medical Faculty and local ethics committees of participating centers approved the study. Patients gave their consent to participate.

\section{Consent for publication}

Not applicable.

\section{Competing interests}

The authors declare that they have no competing interests.

\section{Author details}

${ }^{1}$ Hospital for Children and Adolescents, Centre for Pediatric Research Leipzig $(\mathrm{CPL})$, Department of Women and Child Health, University Hospital, University of Leipzig, Leipzig, Germany. ${ }^{2}$ University Hospital Internal Medicine, University of Leipzig, Leipzig, Germany. ${ }^{3}$ Department of Pediatrics, Klinikum Am Steinenberg, Reutlingen, Germany. ${ }^{4}$ Pediatrics Department of the University Clinic, Münster, Germany. ${ }^{5}$ Department for Inborn Metabolic Diseases, Children's and Adolescents'Hospital, University of Erlangen-Nürnberg, Erlangen, Germany. ${ }^{6}$ Center of Excellence for Rare Metabolic Diseases, Charité, University
Medicin, Berlin, Germany. ${ }^{7}$ Centre for Inborn Metabolic Disorders, Department of Neuropediatrics, Jena University Hospital, Jena, Germany. ${ }^{8} \mathrm{Clinic}$ for Pediatrics, Inherited Metabolic Disorders, Medical University Innsbruck, Innsbruck, Austria. ${ }^{9}$ Clinic for Pediatrics, University Magdeburg, Magdeburg, Germany.

${ }^{10}$ Department for General Pediatrics, Metabolic Unit, University Clinic of the the Justus Liebig University, Giessen, Germany. ${ }^{11}$ Klinikum Cottbus, Cottbus, Germany. ${ }^{12}$ Center of Pediatrics and Adolescent Medicine, University Hospital, Freiburg, Germany. ${ }^{13}$ University Hospital, Greifswald, Germany.

Received: 2 September 2021 Accepted: 6 November 2021

Published online: 18 November 2021

\section{References}

1. Scriver CR, Kaufmann S. The hyperphenylalaninemias: phenxlalanine hydroxylase deficiency. In: Scriver RC, Beaudet AL, Sly WS, Valle D, editors. The metabolic and molecular basis of inherited disease. New York: McGraw-Hill; 2001. p. 1667-724.

2. Burgard P, Bremer HJ, Buhrdel P, Clemens PC, Monch E, Przyrembel H, et al. Rationale for the German recommendations for phenylalanine level control in phenylketonuria 1997. Eur J Pediatr. 1999;158:46-54.

3. van Spronsen FJ, van Wegberg AM, Ahring K, Bélanger-Quintana A, Blau $\mathrm{N}$, Bosch AM, et al. Key European guidelines for the diagnosis and management of patients with phenylketonuria. Lancet Diabetes Endocrinol. 2017:5:743-56.

4. van Wegberg AMJ, MacDonald A, Ahring K, Bélanger-Quintana A, Blau N, Bosch AM, Burlina A, Campistol J, Feillet F, Giżewska M, Huijbregts SC, Kearney S, Leuzzi V, Maillot F, Muntau AC, van Rijn M, Trefz F, Walter JH, van Spronsen FJ. The complete European guidelines on phenylketonuria: diagnosis and treatment. Orphanet J Rare Dis. 2017;12(12):162.

5. Lenke RR, Levy HL. Maternal phenylketonuria and hyperphenylalaninemia. An international survey of the outcome of untreated and treated pregnancies. N Engl J Med. 1980;303:1202-8.

6. Koch R, Friedman E, Azen C, Hanley W, Levy H, Matalon R. The International Collaborative Study of Maternal Phenylketonuria: status report 1998. Eur J Pediatr. 2000;159(Suppl 2):156-60.

7. Mönch E, Link R. Diagnostik und Therapie bei angeborenen Stoffwechsestörungen. 3rd ed. Heilbronn: SPS Verlagsgesellschaft; 2006.

8. Koch R, Hanley W, Levy H, Matalon K, Matalon R, Rouse B, et al. The Maternal Phenylketonuria International Study: 1984-2002. Pediatrics. 2003;112:1523-9.

9. Waisbren SE, Hanley W, Levy HL, Shifrin H, Allred E, Azen C. Outcome at age 4 years in offspring of women with maternal phenylketonuria: the Maternal PKU Collaborative Study. JAMA. 2000;9(283):756-62.

10. ACOG Committee Opinion No. 449. Maternal phenylketonuria. Obstet Gynecol. 2009;114:1432-3.

11. Schwarz M, Wendel U. Inborn errors of metabolism (IEM) in adults. A new challenge to internal medicine. Med Klin. 2005;100:547-52.

12. Trefz FK, van Spronsen FJ, MacDonald A, Feillet F, Muntau AC, BelangerQuintana A, Burlina A, Demirkol M, Giovannini M, Gasteyger C. Management of adult patients with phenylketonuria: survey results from 24 countries. Eur J Pediatr. 2015;174:119-27.

13. Rohr F, Munier A, Sullivan D, Bailey I, Gennaccaro M, Levy H, et al. The resource mothers study of maternal phenylketonuria: preliminary findings. J Inherit Metab Dis. 2004;27:145-55.

14. Unger S, Weigel JF, Stepan H, Baerwald CG. A case of maternal PKU syndrome despite intensive patient counseling. Wien Med Wochenschr. 2009;159:507-10.

15. Antshel KM, Gurian EA, Waisbren SE. Maternal phenylketonuria: a case study suggesting the use of prenatal psychotherapy to help control phenylalanine levels. Am J Orthopsychiatry. 2002;72:577-84.

16. Maillot F, Lilburn M, Baudin J, Morley DW, Lee PJ. Factors influencing outcomes in the offspring of mothers with phenylketonuria during pregnancy: the importance of variation in maternal blood phenylalanine. Am J Clin Nutr. 2008;88:700-5.

17. Walter JH, White FJ. Blood phenylalanine control in adolescents with phenylketonuria. Int J Adolesc Med Health. 2004;16:41-5.

18. MacDonald A. Diet and compliance in phenylketonuria. Eur J Pediatr. 2000;159(Suppl 2):136-41. 
19. MacDonald A, Gokmen-Ozel H, van Rijn M, Burgard P. The reality of dietary compliance in the management of phenylketonuria. J Inherit Metab Dis. 2010;33:665-70.

20. Mütze U, Thiele AG, Baerwald C, Ceglarek U, Kiess W, Beblo S. Ten years of specialized adult care for phenylketonuria - a single center experience. Orphanet J Rare Dis. 2016;11:27.

21. Waisbren SE, Shilo S, St. James P, Levy HL. Psychological factors in maternal phenylketonuria: prevention of unplanned pregnancies. Am J Pub Health. 1991:3:299-304

22. Waisbren SE, Hamilton BD, St. James P, Shilo S, Levy HL. Psychological factors in maternal phenylketonuria: women's adherence to medical recommendations. Am J Pub Health. 1995;12:1636-41.

23. Rohde C, Mutze U, Weigel JF, Ceglarek U, Thiery J, Kiess W, et al. Unrestricted consumption of fruits and vegetables in phenylketonuria: no major impact on metabolic control. Eur J Clin Nutr. 2012;66:633-8.

24. Mütze U, Roth A, Weigel JFW, Beblo S, Baerwald C, Bührdel P, et al. Transition of young adults with phenylketonuria from paediatric to adult care. J Inherit Metab Dis. 2011;34:701-9.

25. Phelan H, Lange K, Cengiz E. Diabetes education in children and adolescence. Pediatr Diabetes. 2018:10(Suppl 27):75-83.
26. Peres M, Almeida MF Pinto ÉJ, Carmona C Rocha S, Guimas A Implementing a transition program from pediatric to adult services in phenylketonuria: results after two years of follow-up with an adult team. Nutrients. 2021;13:799.

27. Feillet F, MacDonald A, Hartung Perron D, Burton B. Outcomes beyond phenylalanine: an international perspective. Mol Genet Metab. 2010;99(Suppl 1):79-85.

28. www. Arbeitsgruppe für angeborene Stoffwechselerkrankungen (uniklinikum-leipzig.de)

29. Resta R. Generation $n+1$ : projected numbers of babies born to women with PKU compared to babies with PKU in the United States in 2009. Am J Med Genet A. 2012;158:1118-23.

30. Berry SA, Brown C, Grant M, Greene CL, Jurecki E, Koch J. Newborn screening 50 years later: access issues faced by adults with PKU. Genet Med. 2013;15:591-9.

\section{Publisher's Note}

Springer Nature remains neutral with regard to jurisdictional claims in published maps and institutional affiliations.
Ready to submit your research? Choose BMC and benefit from:

- fast, convenient online submission

- thorough peer review by experienced researchers in your field

- rapid publication on acceptance

- support for research data, including large and complex data types

- gold Open Access which fosters wider collaboration and increased citations

- maximum visibility for your research: over $100 \mathrm{M}$ website views per year

At $\mathrm{BMC}$, research is always in progress.

Learn more biomedcentral.com/submissions 